\title{
Assessment of Dental Neglect and It's Relation to Oral Health Among School Children Aged 4-12 Years in Sri Ganganagar City, Rajasthan, India
}

\author{
Aniyo Radhe ${ }^{1}$, Neha $^{2}$, Gagandeep Kaur ${ }^{3}$, Nilotpol Kashyap ${ }^{4 *}$, Sanjana Arora ${ }^{1}$ and Sanjeev Kumar ${ }^{2}$ \\ ${ }^{1}$ PG student, Department of Pedodontics and preventive dentistry, Maharaja Ganga Singh dental college and research center, Rajasthan, \\ India \\ ${ }^{2}$ Reader, Department of Pedodontics and preventive dentistry, Maharaja Ganga Singh dental college and research center, Rajasthan ,India \\ ${ }^{3}$ Professor, Department of Pedodontics and preventive dentistry, Maharaja Ganga Singh dental college and research center, Rajasthan,India \\ ${ }^{4}$ Professor, Department of Pedodontics and preventive dentistry, Chitwan Medical College, Nepal
}

*Corresponding author: Kashyap N, Department of Pediatric Dentistry, Chitwan Medical College, Nepal

\begin{abstract}
Background: Dental neglect indicates that parents or guardians fail to give the necessary oral health requirements such that the child can take pleasure in function and free from disease, where reasonable means are accessible to parents or caretaker.

Aim: The aim of the study was to evaluate the dental negligence of parents towards their children aged 4-12 years in Sri Ganganagar city, Rajasthan and to correlate the oral health status of the children.

Materials and Methods: A cross-sectional study was done involving 1000 school going children and their parents. Questionnaire were distributed among the parents of the children which includes the details of parents and their children . WHO form was used to assess the oral health status of the children i.e. the dental caries and bleeding on probing as per the World Health Organization criteria,2013 index. Statistical analysis was done by using SPSS software version 20.0.
\end{abstract}

Results: A significant higher dental negligence score was found among those parents who resided in the suburban area and whose educational qualification was higher secondary only and those who had visited the dentist only after the development of symptoms in their children.

Conclusion: Among the parents whose educational qualification was higher secondary only, those who resided in the suburban area and those who went to see dentist only after the development of symptoms in their children have shown poor health status.

Keywords: Dental neglect; dental caries; oral hygiene; parents

\section{Introduction}

Dental neglect indicates that how known knowledge of oral health care are not fulfilled which fails to do the proper maintenance of oral cavity. For proper oral health care people need to be aware of the dental problem consequences. In spite of giving so much dental professionals and audio-visual dental care measures, only a small number of people take proper dental home care and they do not go for periodic dental checkup. Oral health is considered as the central importance for our general health and well-being. A healthy oral cavity allows an individual to communicate, have food and participate in social activities without having any disease, discomfort or difficulty. Having oral disease can be expensive in terms of money and also life style can be changed [1]. The World Health Organization has stated that neglect should be differentiated from conditions like poverty, where it shows dental neglect is present only where there are available resources. It was found that there is a great deal of severity of dental neglect worldwide [2].

\section{Materials and Methods}

Ethical approval for the study were taken from the concerned authority of the institution. This ensured that participants involved in the study were randomly selected from the schools of Sri Ganganagar city. This study was conducted from January 2019 
to August 2019. The age of the children were 4 to 12 years, and the questionnaire were given to the parents of the children to be answered. An informed consent was obtained from the parents earlier. The parents were asked to answer the questionnaire which had details of both parents and children. Consent form from parents were taken for the survey to be done. Oral examination of children was conducted by using disposable mouth mirror, straight probe and CPTIN probe in a natural day light. Oral status was recorded according to the WHO form, 2013. The collected data were tabulated and subjected to statistical analysis using SPSS software version 20.0, (SPSS Inc., Chicago Ill., USA) and levels of statistical significance were set at $\mathrm{P}<0.05$.

\section{Results}

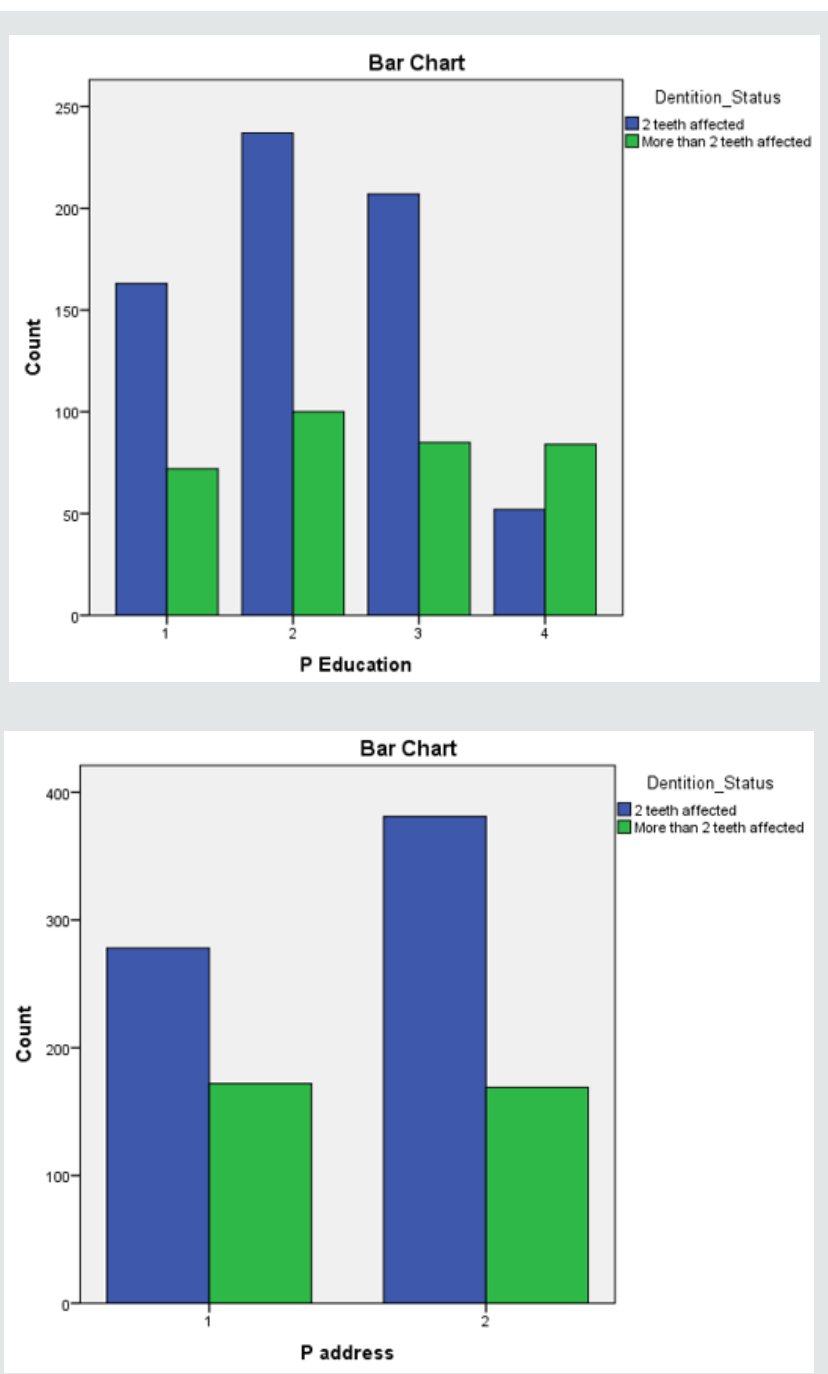

Graphs 1\&2: Shows the address and parental education level.

A total of 1000 pair of parents and children participated in the study, of which female and male parents were of 631 and 369 , respectively. Table 1 illustrate the comparison of key background variables and dental service used in previous two years and Table 2 shows the $\mathrm{p}$ value for the oral status with respect to key background variables (Graphs 1\&2). It is showed that with respect to dental neglect scores, a significant higher dental neglect score was reported among the people who resided in the suburban location, parents whose educational qualification was higher secondary only, parents whose visit to the dentist were only after the development of symptom, parents those who used only school dental services and those who used dental service only once in previous two years.

Table 1: Comparison of key background variables with respect to given demographic status.

\begin{tabular}{|c|c|c|}
\hline & $\mathbf{N}$ & Mean DNS score \\
\hline \multicolumn{3}{|c|}{ Education } \\
\hline Secondary & 235 & $23.50 \%$ \\
\hline Higher secondary & 337 & $33.7 \%$ \\
\hline Graduate & 295 & $29.50 \%$ \\
\hline Post graduate & 136 & $13.60 \%$ \\
\hline \multicolumn{3}{|c|}{ Address } \\
\hline Urban & 450 & $45 \%$ \\
\hline Suburban & 550 & $55 \%$ \\
\hline \multicolumn{3}{|c|}{ Parental visiting pattern to the dentist } \\
\hline Routine & 415 & $41.50 \%$ \\
\hline Symptom driven & 585 & $58.50 \%$ \\
\hline \multicolumn{3}{|c|}{ Dental services used in previous two years } \\
\hline School dental service only. & 346 & $34.60 \%$ \\
\hline Private dentist only. & 381 & $38.10 \%$ \\
\hline Both types & 173 & $17.30 \%$ \\
\hline Neither types & 100 & $10 \%$ \\
\hline \multicolumn{3}{|c|}{ Times of dental services used in previous two years } \\
\hline 1 & 606 & $60.60 \%$ \\
\hline 2 & 315 & $31.50 \%$ \\
\hline 3 & 79 & $7.90 \%$ \\
\hline
\end{tabular}

Table 2:

\begin{tabular}{|c|c|c|}
\hline P value & $\begin{array}{c}\text { Carious } \\
\text { Teeth }\end{array}$ & $\begin{array}{c}\text { Gingival } \\
\text { Bleeding }\end{array}$ \\
\hline Address & $0.013^{*}$ & 0.696 \\
\hline Education & $0.000^{* *}$ & $0.000^{* *}$ \\
\hline Parental visiting pattern to the dentist & 0.067 & 0.678 \\
\hline Dental services used in previous two years & $0.016^{*}$ & $0.000^{* *}$ \\
\hline $\begin{array}{c}\text { Times of dental services used in previous } \\
\text { two years }\end{array}$ & $0.005^{*}$ & $0.043^{*}$ \\
\hline
\end{tabular}

${ }^{*} \mathrm{P}$ value is statistically significant, ${ }^{* *} \mathrm{P}$ value is statistically highly significant.

\section{Discussion}

Oral health occupies a very significant role for the wellbeing of individuals, and parents' behavior and way of thinking influence the oral health of their children [3]. Prevention is always better option than cure. People should be very thoughtful and particular to maintain oral health for the prevention of oral disease. Dental professionals and audio-visual media provide the essential dental care measures [4]. But the fact is that only few people take adequate regular home dental care and do not go for periodic/yearly dental 
check to the dentist to keep their oral cavity healthy [5]. It has been seen that dental neglect is mostly related to the illiteracy amongst low socio-economic class and the prevalence of oral diseases are highest amongst them [6]. Child neglect is a very important subject in terms of prevalence and severity-it is the most common cause for a child to be made subject to a child protection plan in the UK - and there is indubitable evidence and facts that it is harmful and damaging to children [7-10]. There is very scarce literature regarding the estimate of child dental neglect worldwide [11]. Hence, in this study, in addition to recording the caries status, the gingival status i.e. bleeding on probing was also evaluated which interprets the degree of failure to seek dental treatment. Out of 1000 children maximum number of the participants were 7 years with 596 male and 404 females. Majority of the children were in 1st standard and from private school. The caretakers who responded to the questionnaire were mostly mothers of the children. Hence, it helped us to know the complete home and professional dental care the child receives as the child is mostly with the mother. The results of the present study showed that dental neglect was found more in parents who have done only higher secondary education which showed lesser levels of positive dental attitudes which is in contrary to the result of Gurunathan D et al. [12] where it was stated that parents who have done secondary education showed lesser levels of positive dental attitudes which is similar to studies done by Freeman et al. and Williams et al. $[13,14]$. In the present study, a significant difference was observed in the dental neglect scores among parents residing in the suburban areas in comparison with parents of urban areas. This is essentially due to not much awareness of oral health, availability, and usage of dental services [15]. The dental neglect among children is higher among parents' whose last dental visit was once or twice in previous 2 years, those who used only school dental services and were symptom driven which is similar to the findings in South Australia and Chennai [16]. The dental neglect is reflected in the poor oral health of these children with significantly higher caries prevalence and untreated carious lesions. This suggests that the knowledge of parents regarding oral health and utility of dental services is limited as the frequency of dental visits suggests the oral health awareness among parents [17]

\section{Conclusion}

Inadequate dental care by parents can be observed as dental neglect in children and therefore is a sign of child neglect. Health care workers involved in the care of children are thus in a unique and a very important position to understand early symptoms of child abuse and neglect. We believe and accept that the occurrence of dental caries is an important sign to this diagnosis. From this study it is concluded that, the dental neglect among school going children aged 4-12 years regarding oral hygiene is still far from satisfactory in certain respects in our population, but it is also seen that oral hygiene status can be improved after sessions of oral health education to the children and most importantly the parents.

\section{References}

1. Kwan SY, Petersen PE, Pine CM, Borutta A (2005) Health-promoting schools: an opportunity for oral health promotion. Bull World Health Organ 83(9): 677-685.

2. Bhatia SK, Maguire SA, Chadwick BL, Hunter ML, Harris JC, et al. (2014) Characteristics of child dental neglect: a systematic review. J Dent 42(3): 229-239.

3. Abiola Adeniyi A, Eyitope Ogunbodede 0, Sonny Jeboda O, Morenike Folayan 0 (2009) Do maternal factors influence the dental health status of Nigerian pre-school children? Int J Paediatr Dent 19(6): 448-454.

4. Syrjala AMH, Knuuttila MLE, Syrjala LK (1992) Reasons preventing regular dental care. Community Dent Oral Epidemiol 20: 10-14.

5. Durward CS, Wright FAC (1989) Dental knowledge, attitude and behaviours of Indo-Chinese and Australian born adolescence: Community Dent Oral Epidemiol 17(1): 14-18.

6. Airen B, Dasar P, Nagarajappa S, Kumar S, Jain D, et al. (2014) Dentition status and treatment need in urban slum dwellers in Indore city, Central India. J Indian Assoc Public Health Dent 12: 163-166.

7. Dubowitz H, Newton RR, Litrownik AJ, Lewis T, Briggs EC, et al. (2005) Examination of conceptual model of child neglect. Child Maltreat 10(2): 173-189.

8. Lazenbatt A (2010) The impact of abuse and neglect on the health and mental health of children and young people.

9. Freeman R (2005) The role of the primary care dentist in safeguarding children. In Safeguarding Children in Primary Health Care. Taylor J, Themessl Huber M (Eds.), Jessica Kingsley, London, UK, pp. 60-76.

10. Lazenbatt ABL, Taylor JS (2012) The consequences of infant maltreatment on children's future health and well-being. British J Mental Health Nursing 1(3): 171-175.

11. Bhatia SK, Maguire SA, Chadwick BL, Hunter ML, Harris JC, et al. (2014) Characteristics of child dental neglect: A systematic review. J Dent 42(3): 229-239.

12. Gurunathan D, Shanmugaavel AK (2016) Dental neglect among children in Chennai. J Indian Soc Pedod Prev Dent 34(4): 364-369.

13. Freeman R, Breistein B, McQueen A, Stewart M (1997) The dental health status of five-year-old children in north and west Belfast. Community Dent Health 14(4): 253-257.

14. Williams NJ, Whittle JG, Gatrell AC (2002) The relationship between socio demographic characteristics and dental health knowledge and attitudes of parents with young children. Br Dent J 193(11): 651-654.

15. Suresh BS, Ravishankar TL, Chaitra TR, Mohapatra AK, Gupta V (2010) Mother's knowledge about pre-school child's oral health. J Indian Soc Pedod Prev Dent 28(4): 282-287.

16. Thomson WM, Spencer AJ, Gaughwin A (1996) Testing a child dental neglect scale in South Australia. Community Dent Oral Epidemiol 24(5): 351-356.

17. Silver DH (1992) A comparison of 3-year-olds' caries experience in 1973 1981 and 1989 in a Hertfordshire town, related to family behaviour and social class. Br Dent J 172(5): 191-197. 
(C) (i) This work is licensed under Creative Commons Attribution 4.0 License

To Submit Your Article Click Here: Submit Article

DOI: $10.32474 /$ IPDOAJ.2020.03.000171

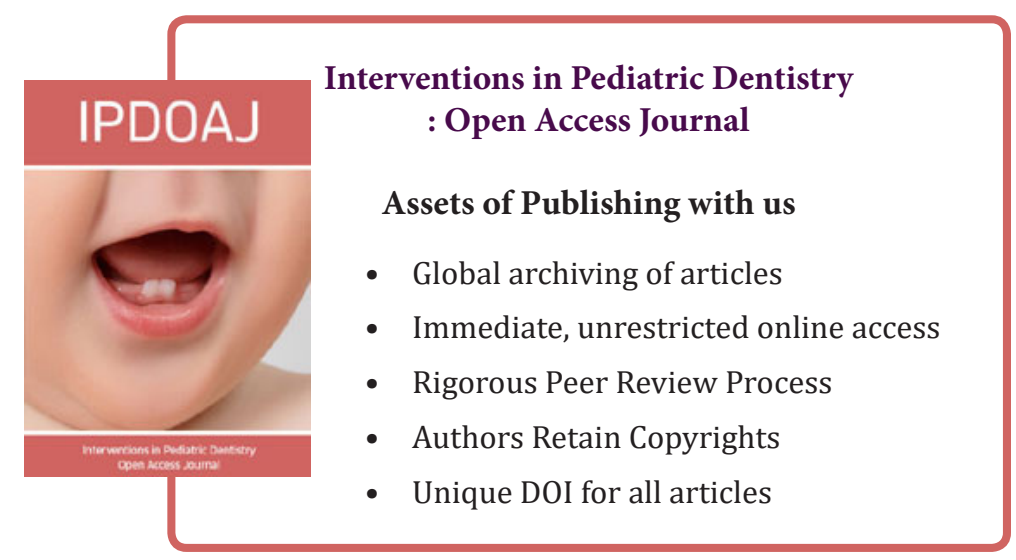

